\title{
A SEISMIC REFLECTION SURVEY TO HELP DETERMINE THE ICE THICKNESS ON THE LOBBIA GLACIER, ADAMELLO MASSIF, ITALY.
}

\author{
L. Levato', L. Veronese ${ }^{2}$, A. Lozej ${ }^{3}$, E. Santuliana ${ }^{2}$, E. Tabacco ${ }^{3}$ \\ Institut de Géophysique, Université de Lausanne, Collège Propédeutique, 1015 Lausanne, \\ Switzerland \\ ${ }^{2}$ Laboratorio Geotecnico, Servizio Geologico della Provincia Autonoma di Trento, Via \\ Sanseverino 137,38100 Trento , Italy \\ ${ }^{3}$ Istituto di Geofisica, Università di Milano, Via Cicognara 7, 20129 Milano, Italy
}

\begin{abstract}
In the framework of a geophysical study to investigate the ice thickness on the Lobbia Glacier located in the Adamello Massif, Italy, we recorded $1393 \mathrm{~m}$ of 2D multifold seismic data, in summer 1996, to constrain a joint gravity survey covering an area of about $4 \mathrm{~km}^{2}$.

Single fold seismic data (Tabacco, Pettinicchio, and Veronese 1995), and gravity data (Olivier et al., 1996), collected during previous surveys, provided an estimate of the maximum ice thickness.

The main processing sequences include band-pass filtering, $f-k$ filtering, residual static corrections, stack, deconvolution and migration.

The contact between the ice and the granite substratum appears as a strong reflection at a maximum two way time of $105 \mathrm{~ms}$.
\end{abstract}

\section{INTRODUCTION}

Global climate change studies need the estimation of the volume of glaciers and ice sheets and the monitoring of their evolution in time. Ground penetrating radar would seem the most appropriate geophysical tool to carry out this kind of investigations, since the first GPR experiments were done in Antarctic to measure the ice thickness (Cook, 1995). However, the ice of temperate glaciers may be less transparent to electromagnetic waves than that of the polar ice sheets (Tabacco, Pettinicchio, and Veronese, 1995 and therein references). GPR surveys on the Lobbia glacier provided a good image of the ice-bedrock contact only to a depth of $40 \mathrm{~m}$. Therefore, a joint gravity and seismic survey was organised in order to determine a 3D model of the ice-bedrock interface (Rosselli et al., 1997, this volume). Gravity measurements are relatively fast to collect, but their interpretation can be quantitative provided the density contrast is known and the regional trend of the gravity anomaly is constrained by independent data. Collecting seismic data is much longer than collecting gravity data, but they may provide a quantitative estimation of the ice thickness. For these reasons, the gravity measurements covered the entire region (Rosselli et al., this volume), while the seismic data were collected along two profiles, $1071 \mathrm{~m}$ and $322 \mathrm{~m}$ long.

The main profile is transversal to the axis of the glacier, which has an approximate orientation $\mathrm{N}$ to $\mathrm{S}$, and according to a preliminary interpretation of previously collected gravity data 
(Olivier et al., 1996), runs over the maximum ice thickness, which is of the order of $200 \mathrm{~m}$. The short profile, recorded for control purposes, runs parallel to the axis of the glacier and intersect the main profile in the central part.

\section{ACQUISITION, PROCESSING, AND RESULTS}

Transportation of equipment and people at the base located at an altitude of about $3000 \mathrm{~m}$, was provided by a helicopter of the Fire Department of Trento (Italy).

The acquisition lasted about one day and a half, employing 4 to 5 people. To speed up the acquisition, a sledge was used to move the geophones and the cables along the seismic lines.

A total of 372 stations of $40 \mathrm{~Hz}$ geophones spaced at $3 \mathrm{~m}$ interval, were deployed along the main profile. We used a modified " buffalo gun ", firing industrial cartridges (8 gauges) every $12 \mathrm{~m}$. The shots were recorded for $200 \mathrm{~ms}$, over 24 channels by a Geometrics ES-2401 exploration seismograph, which yielded a 3 nominal fold. The same acquisition configuration was used for the 124 stations of the short profile.

The data were processed on a Sparc10 Sun workstation with GeovecteurPlus (CGG) commercial software.

A strong reflection is present on all the shots at a maximum time of about $100 \mathrm{~ms}$, however F-K filter was needed to suppress strong coherent low-velocity noise contaminating this reflection (Figure 1). Residual static corrections considerably improved the continuity of the reflection. Deconvolution and migration were essential to obtain a good vertical and horizontal resolution (Figure 2).

On the main profile, the contact between the ice and the granite substratum appears as a strong reflection at a two way time varying from about $50 \mathrm{~ms}$ to the west and to the east, to about $100 \mathrm{~ms}$ in the central part, over $500 \mathrm{~m}$. The image on the short profile does not show major changes in the topography of the ice-granite contact over the investigated distance.

\section{REFERENCES}

Cook, J.C., 1995. Preface. In: « Owen, T.E. Ed., Ground Penetrating Radar », Applied Geophysics, Special Issue, 33, nos.1-3, p.1-3.

R. Olivier, A. Rosselli, Ph. Logean, B. Dumont, A. Re, Ph. Rosset, E. Tabacco, N. Tosi, L. Veronese, E. Santuliana, G. Manzoni, and R. Cefalo. 1996. Ice depth determination by gravity measurements on the Lobbia glacier (Adamello massif, Italy). Book of abstracts of the International Congress on Environment/Climate, ICEC-96, March 4-8, 1996, Rome, Italy, p. 163 (abstract).

A. Rosselli, R. Olivier, E. Tabacco, R. Cefalo, B. Dumont, Ph. Logean, Ph. Rosset, M. Manzoni, M. Pavan, and S. Urbini, 1997. 3D Modeling of the Lobbia glacier bedrock (Adamello Massif, Italy) using gravity and GPS measurements (this volume).

E. Tabacco, P. Pettinicchio, and L. Veronese, 1995. Radar and seismic survey on temperate glaciers in northern Italy, Adamello and Stelvio Glacier. Proceedings of the EEGS 1st Meeting, September, 25-27th, 1995, Torino, Italy, p.190-197 (extended abstract). 
CDP

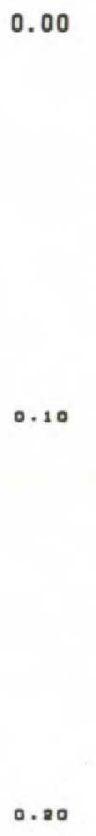

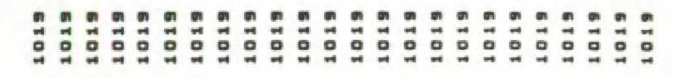

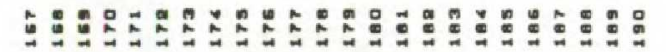

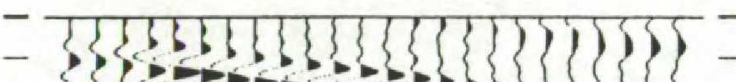

$\rightarrow \rightarrow \rightarrow-\rightarrow\}\{\}\{\}$

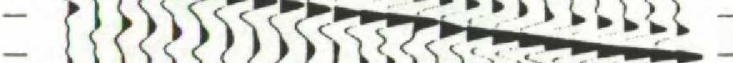

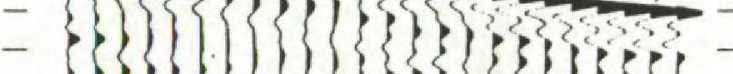

$-23\}$

$-\{3 \sin 3$

- \{rof \{\}$\{\{\}\{\}\{\{\{\}\{\}\}-$

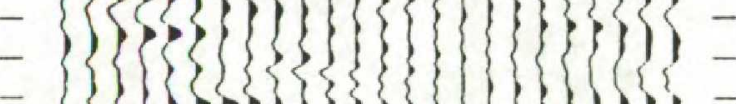

$-\{\{\{\{\leq<\}\}\{\}\{\{\{\{\}, 1\}\{-$

$\longrightarrow \rightarrow-10 \Rightarrow$ $\rightarrow 33355\{\leq \rightarrow \leq\} 3\{25$

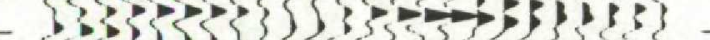
$-\{\{\{\{\}\{\{\{\{\}\{\}\}\} \Rightarrow-1\}$

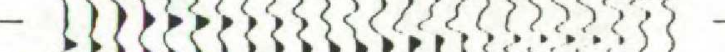

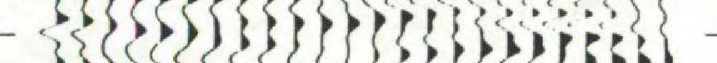

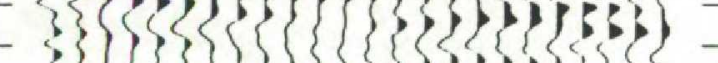

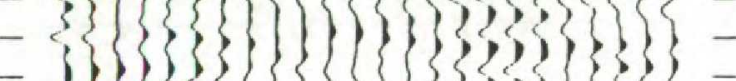

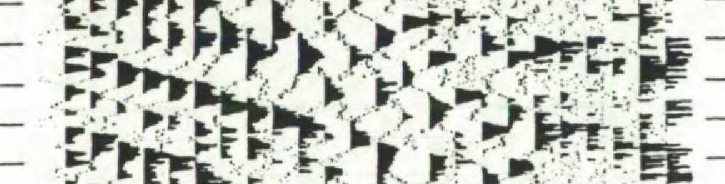

(a)

(b)

Figure 1. a) Raw shot gather; b) same shot gather after F-K filter. Geophone spacing: 3m. 


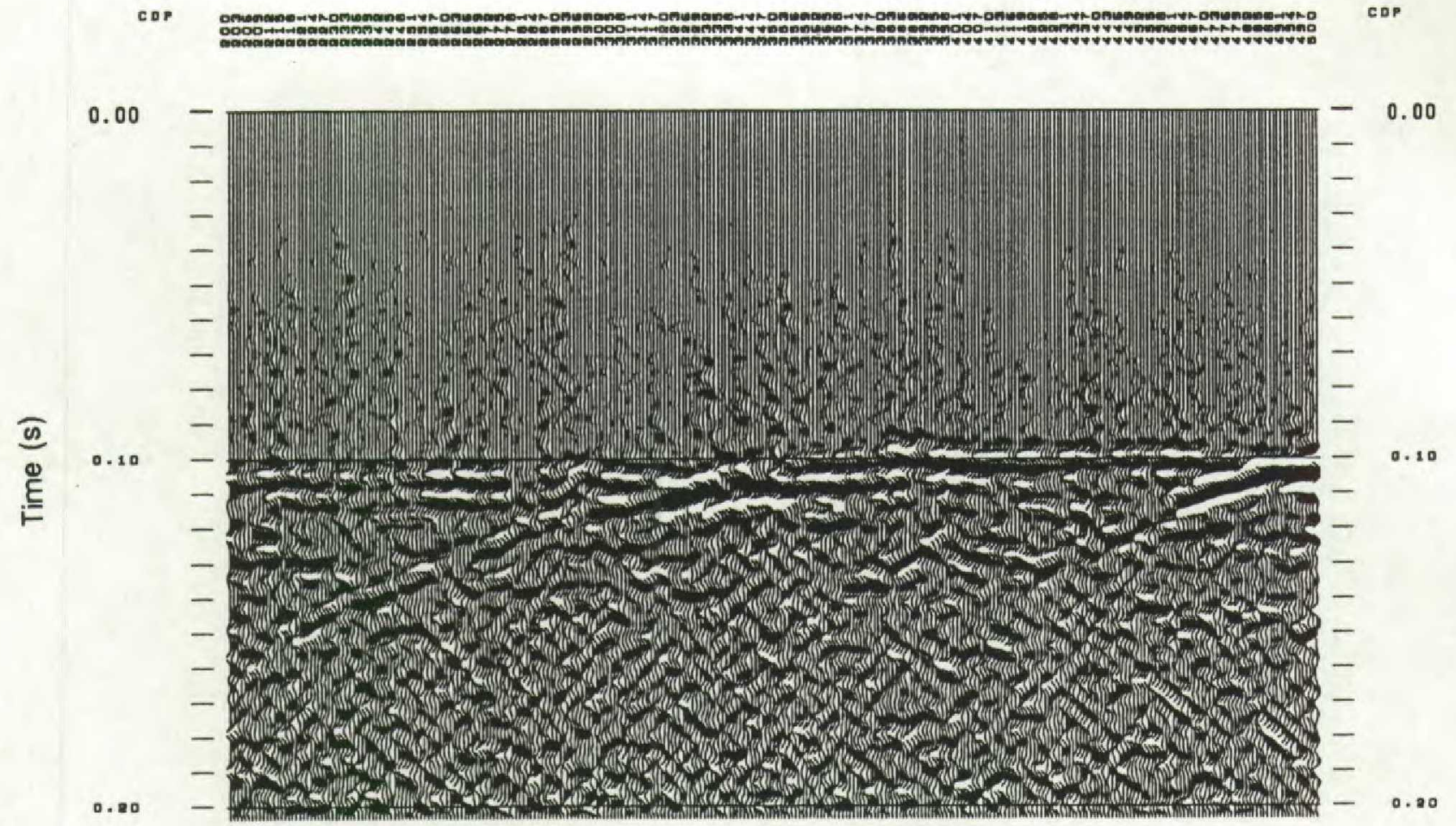

(a)

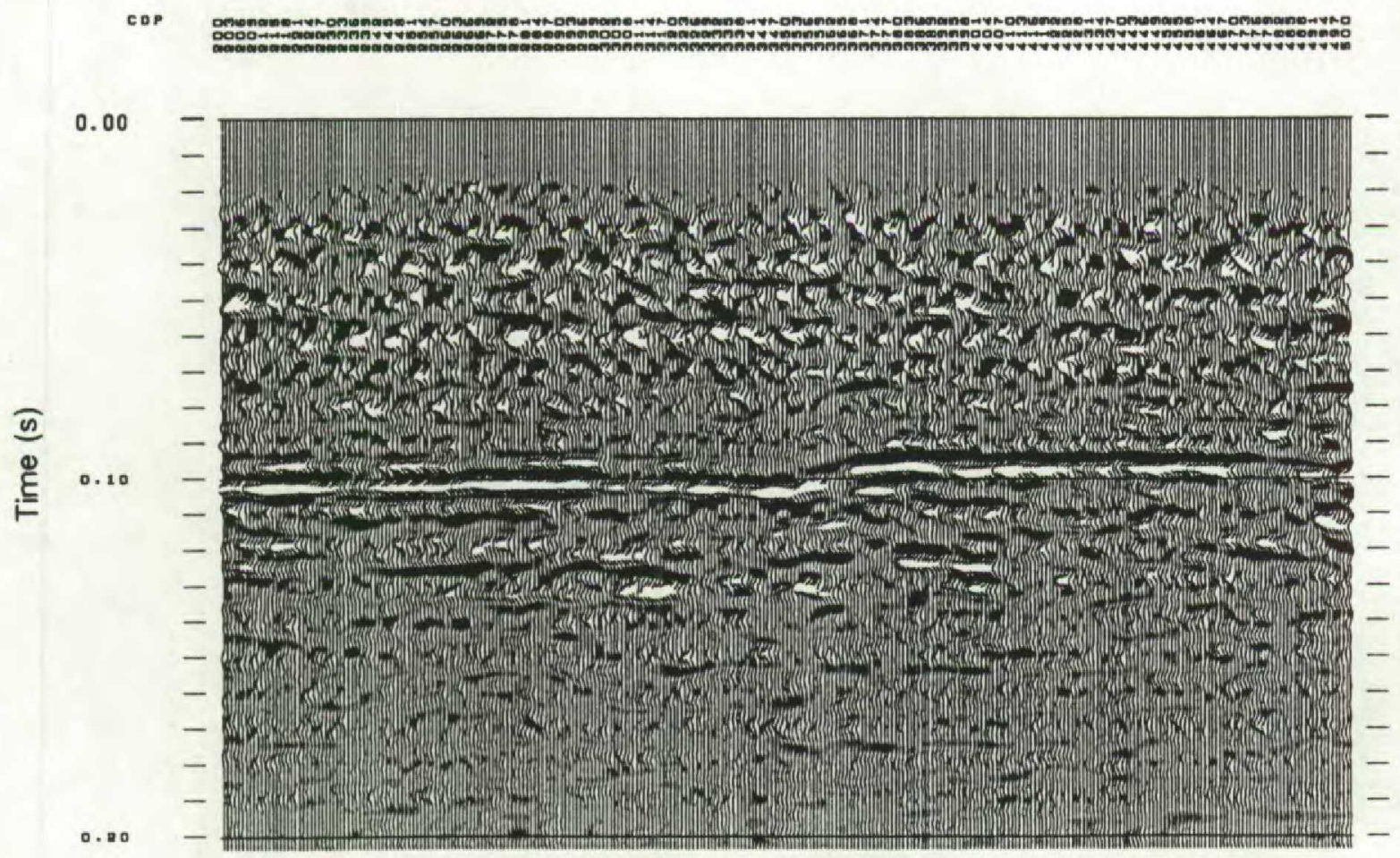

Cor

0.00

(b)

Figure 2. a) Window of the stacked section; b) same window after deconvolution and migration. CMP spacing: $1.5 \mathrm{~m}$. 